\title{
Between Inflammation and Autophagy: The Role of Leptin-Adiponectin Axis in Cardiac Remodeling
}

\author{
Layla Kamareddine ${ }^{1-3}$ \\ Crystal M Ghantous ${ }^{4}$ \\ Soumaya Allouch ${ }^{5}$ \\ Sarah A Al-Ashmar 2,5 \\ Gulsen Anlar ${ }^{2,5}$ \\ Surya Kannan $\mathbb{D}^{2,5}$ \\ Laiche Djouhri $\mathbb{D D}^{2,5}$ \\ Hesham M Korashy (D) $^{2,6}$ \\ Abdelali Agouni (D) ${ }^{2,6}$ \\ Asad Zeidan ${ }^{2,5}$
}

'Department Biomedical Sciences, College of Health Sciences, QU Health,

Qatar University, Doha, Qatar;

${ }^{2}$ Biomedical and Pharmaceutical Research

Unit, QU Health, Qatar University, Doha,

Qatar; ${ }^{3}$ Biomedical Research Center,

Qatar University, Doha, Qatar;

${ }^{4}$ Department of Nursing and Health

Sciences, Faculty of Nursing and Health

Sciences, Notre Dame University-

Louaize, Keserwan, Lebanon;

${ }^{5}$ Department of Basic Sciences, College

of Medicine, QU Health, Qatar

University, Doha, Qatar; ${ }^{6}$ Department of Pharmaceutical Sciences, College of

Pharmacy, QU Health, Qatar University, Doha, Qatar
Correspondence: Asad Zeidan

Department of Basic Sciences, College of Medicine, QU Health, Qatar University,

Doha, Qatar

Email a.zeidan@qu.edu.qa

\begin{abstract}
Cardiac remodeling is the process by which the heart adapts to stressful stimuli, such as hypertension and ischemia/reperfusion; it ultimately leads to heart failure upon longterm exposure. Autophagy, a cellular catabolic process that was originally considered as a mechanism of cell death in response to detrimental stimuli, is thought to be one of the main mechanisms that controls cardiac remodeling and induces heart failure. Dysregulation of the adipokines leptin and adiponectin, which plays essential roles in lipid and glucose metabolism, and in the pathophysiology of the neuroendocrine and cardiovascular systems, has been shown to affect the autophagic response in the heart and to contribute to accelerate cardiac remodeling. The obesity-associated protein leptin is a pro-inflammatory, tumor-promoting adipocytokine whose elevated levels in obesity are associated with acute cardiovascular events, and obesity-related hypertension. Adiponectin exerts anti-inflammatory and antitumor effects, and its reduced levels in obesity correlate with the pathogenesis of obesityassociated cardiovascular diseases. Leptin- and adiponectin-induced changes in autophagic flux have been linked to cardiac remodeling and heart failure. In this review, we describe the different molecular mechanisms of hyperleptinemia- and hypoadiponectinemia-mediated pathogenesis of cardiac remodeling and the involvement of autophagy in this process. A better understanding of the roles of leptin, adiponectin, and autophagy in cardiac functions and remodeling, and the exact signal transduction pathways by which they contribute to cardiac diseases may well lead to discovery of new therapeutic agents for the treatment of cardiovascular remodeling.
\end{abstract}

Keywords: inflammation, autophagy, leptin, adiponectin, cardiac cells

\section{Introduction}

The World Health Organization (WHO) classifies cardiovascular diseases as the leading cause of death worldwide, with an estimated 17.9 million annual deaths attributed to this class of diseases. ${ }^{1}$ Risk factors of cardiac remodeling, hypertrophy, and heart failure are various; however, hypertension is a crucial player in the pathogenesis of these conditions. ${ }^{2}$ Hypertension induces increased mechanical stretch of the vascular smooth muscle cells. ${ }^{3}$ The ability of the cardiac muscle to sense and respond to mechanical stretch occurs through a process known as mechanotransduction, which is the conversion of mechanical triggers into biochemical incidents. ${ }^{4}$ This, in turn, causes a change in myocardial function and structure as a compensatory mechanism during adaptation to the trigger. ${ }^{5}$ In the case of prolonged stimuli, signal transduction occurs and the whole process becomes maladaptive, causing a change in the physiology of the heart, and subsequently leading to development of cardiac remodeling/hypertrophy. ${ }^{5,6}$ 
Leptin and adiponectin are physiologically essential for glucose and lipid metabolism, as well as neuroendocrine and cardiovascular functions. However, at dysregulated levels, they are considered major contributors to the pathogenesis of heart failure. ${ }^{7}$ The biological characteristics of the aforementioned adipokines are contradictory. Explicitly, adiponectin triggers potent anti-inflammatory and anti-tumor responses as opposed to the pro-inflammatory and tumor-promoting features of leptin. ${ }^{8}$ Although the effects of adiponectin and leptin on cardiac remodeling are multifactorial in nature, recent studies have reported that they take place through the induction of autophagy. ${ }^{8}$ Autophagy, a cellular catabolic process, was originally considered a mechanism of cell death in response to detrimental stimuli. ${ }^{9}$ However, recent studies have reported a vital role of autophagy in controlling the cardiac hypertrophic response and the pathogenesis of heart failure. ${ }^{9,10}$ In this review, we summarize the different mechanisms involved in the development and progression of cardiac dysfunctions, highlight the roles of adiponectin, leptin, and autophagy in the pathogenesis of cardiac diseases, and illustrate the interplay between all of the abovementioned pathways.

\section{Cardiac Remodeling}

The molecular mechanisms underlying cardiovascular remodeling produce significant changes in the function of the cardiovascular system, leading to cardiovascular dysfunction. Such alterations include cardiac contractility dysfunction, hypertrophy, fibrosis, and inhibition of the autophagic process.

Cardiac remodeling can be described as a physiologic and pathologic condition that affects cardiac function and structure. It occurs in response to several factors, such as inflammation and vascular and cardiomyocyte hypertrophy, and is a complex process that involves cardiomyocyte growth and death, fibrosis and electrophysiological changes. ${ }^{11}$ It includes cellular and interstitial modifications of the heart, clinically established by changes in cardiac function and structure/size/wall thickness. Cardiac remodeling occurs due to biomechanical stresses and pathological stimuli. ${ }^{12}$ Scarred tissue, fibrosis, and inflammatory infiltrate are also detectable in a remodeling heart.

Heart failure is the major complication of cardiac remodeling. It starts at cellular-level changes that occur due to a remodeling-inducing stimulus, leading to cellular and molecular alterations; these changes, in turn, contribute to progressive ventricular dysfunction, which is originally asymptomatic but with time, induces heart failure. ${ }^{13}$ Cardiac dysfunction and failure occur in response to excessive sympathetic nervous system and angiotensin system stimulations, which activate signal transduction pathways that increase the production of cardiac hypertrophic proteins in cardiomyocytes. ${ }^{14}$

Cardiac remodeling is also associated with a major increase in the production of reactive oxygen species (ROS). ROS can lead to several factors that induce cardiac remodeling; these include DNA damage, protein oxidation, activation of matrix metalloproteinases, lipid peroxidation, cellular dysfunction, and enhancement of cardiomyocyte apoptosis. ${ }^{15}$

Autophagy (which we discuss in detail below) is a natural catabolic mechanism in which lysosomes degrade any damaged or unnecessary components in the cell. This process can result in the accumulation of defective proteins, leading to proteotoxicity. ${ }^{16}$ Research has shown that autophagy is another process that leads to cardiac remodeling. ${ }^{17}$

In addition, microRNA-22 (miR-22) has emerged as an important regulator of cardiovascular remodeling. MiR-22 has been reported as a crucial modulator of the expression of genes involved in cardiac hypertrophy, actin cytoskeleton reorganization, and metabolic pathways leading to cardiovascular remodeling. ${ }^{4}$

During cardiac remodeling, changes occur in the calcium transport system; these include a decrease in L-type calcium channels, calsequestrin and calmodulin kinase activity, and phospholamban phosphorylation, leading to reduced calcium supply during cardiac contraction and increased supply during diastole. Consequently, the modifications in the calcium transit proteins may contribute to cardiac dysfunction. ${ }^{18}$

Moreover, collagen content plays an important role in maintaining cardiac architecture and function. During cardiac remodeling, an imbalance may occur between the synthesis and degradation of collagen, resulting in increased myocardial stiffness and decreased coronary flow. ${ }^{18,19}$

\section{Hypertension, Cardiac Hypertrophy, and Heart Failure}

Cardiac hypertrophy is a way by which the heart adapts to hypertension. This response alters the myocardial structure in a way that vastly contributes to cardiovascular mortality, unexpected death, heart failure, and stroke. ${ }^{20}$ Initially, 
hypertrophy is beneficial because it induces the production of a stronger contractile force and retrieves the normal wall stress caused by the increased systolic pressure in the heart. However, upon long-term stimulation, hypertrophy not only increases myocytes' size, but also causes undesirable reprogramming in gene expression, which ultimately leads to heart failure. ${ }^{21}$

Although cardiac hypertrophy can be induced by many stimulants, including neuronal and hormonal factors, hypertension (mechanical stretch) is considered to be the most common cause of this state. ${ }^{22}$ Eventually, long-term hypertension leads to heart failure, and in most cases, patients with heart failure have a history of hypertension. ${ }^{21}$ Before converting the increased mechanical stretch in response to prolonged hypertension into a biological signal, the cardiomyocyte senses this stretch first. Three sensing systems exist in the cardiac cells: Focal adhesion components, specialized proteins found on the plasma membrane, and sensing proteins found in the cardiac $\mathrm{Z}$ line. ${ }^{6}$ In turn, intracellular signal transduction gets activated, resulting in cardiac hypertrophy.

Many studies have investigated the potential e-link between chronic stretch (hypertension), hypertrophy, and heart failure at the molecular level. Herein, we review the possible pathways accounting for cardiac hypertrophy and the role of two adipokines, leptin and adiponectin, in these mechanisms. Myocardial infarction, the irreversible death of the cardiac muscle, is an important factor that enhances the transition from hypertension to heart failure. ${ }^{23,24} \mathrm{In}$ animal models, the cellular pathogenesis through which myocardial infarction leads to heart failure is well studied. The process is characterized by early ischemia, cardiomyocyte remodeling, and edema development. Together, these would initiate progressive cell death within three hours of myocardial infarction. ${ }^{23,24}$ Oxidative stress and calcium overload also cause reversible acute contractile dysfunction.

\section{Adipokines and Inflammation}

Obesity induces a state of dysfunction in adipose tissue, leading to upregulated secretion of pro-inflammatory adipokines and downregulated production of anti-inflammatory adipokines. The collective effect of obesity-induced adipose tissue dysfunction is the pathogenesis of several diseases, including hypertension and cardiovascular disease. ${ }^{25}$ Adipokines are secreted by adipocytes and are important proteins of various metabolic processes. Adipocytes secrete bioactive substances related to inflammation (Figure 1), including tumor necrosis factor$\alpha$ (TNF- $\alpha$ ), interleukin (IL)-6, hapto-globin, nerve growth factor, and macrophage migration factor. Moreover, C-reactive protein (CRP) has been shown to be synthesized by adipose tissue, and its mRNA expression was found to be upregulated in the adipose tissue of adiponectin knockout mice. ${ }^{26}$ The increased expression of these inflammation-associated adipocytokines has been implicated in the pathogenesis of cardiovascular disease. ${ }^{27}$ Specifically, these adipocytokines play an important role in the extensive crosstalk between adipose tissue, other organs, and various metabolic systems.

Adipokines play an important role in regulating vascular tone. For instance, the adipokines adiponectin, visfatin, omentin, and the unidentified adipocyte-derived relaxing factor (ADRF) exert vasorelaxing effects on the vascular wall. $^{28}$ On the other hand, resistin and angiotensin II, which are also released by adipocytes, exert vasoconstricting effects. ${ }^{28}$ In addition, adipose tissue-secreted leptin, ROS, apelin, tumour necrosis factor $\alpha$, and interleukin-6 share both vasoconstricting and vasorelaxing properties. ${ }^{29}$ A dysregulation in the release of pro-inflammatory and vasoactive adipokines is a key factor leading to the pathophysiological vascular reactivity observed in obesity and obesity-related disorders.

\section{Leptin as a Pro-Inflammatory Cytokine}

Leptin is the first adipokine (obesity-associated protein) identified in $1994 .^{30,31}$ It is a $16 \mathrm{kDa}$ protein that helps regulate energy balance by controlling food intake via its actions on the hypothalamus. Even though the leptin gene is highly expressed in adipose tissues, it can also be expressed at other sites like mammary epithelial cells, bone marrow, and vascular smooth muscle cells. ${ }^{32,33}$ In a healthy state, leptin controls blood pressure by regulating sympathetic activity-dependent vasoconstriction and the endothelial release of nitric oxide (NO), as well as angiotensin II (Ang II)-dependent vasoconstriction. ${ }^{34}$

The physiological activity of leptin strongly depends on its binding to its $\mathrm{Ob}-\mathrm{R}$ receptors (Figure 2). These receptors are expressed in six isoforms, and according to their structural differences, they are classified into three classes: Long, short, and secretory. The extracellular domain is common for all isoforms, but the intracellular domain is variable. Ob-Ra, Ob-Rc, Ob-Rd, and Ob-Rf are short isoforms. Ob-Re is soluble and can bind to circulating leptin, thus regulating the free leptin concentration. $\mathrm{Ob}-\mathrm{Rb}$ is the long isoform with the longest intracellular 


\section{Adipocytokine}

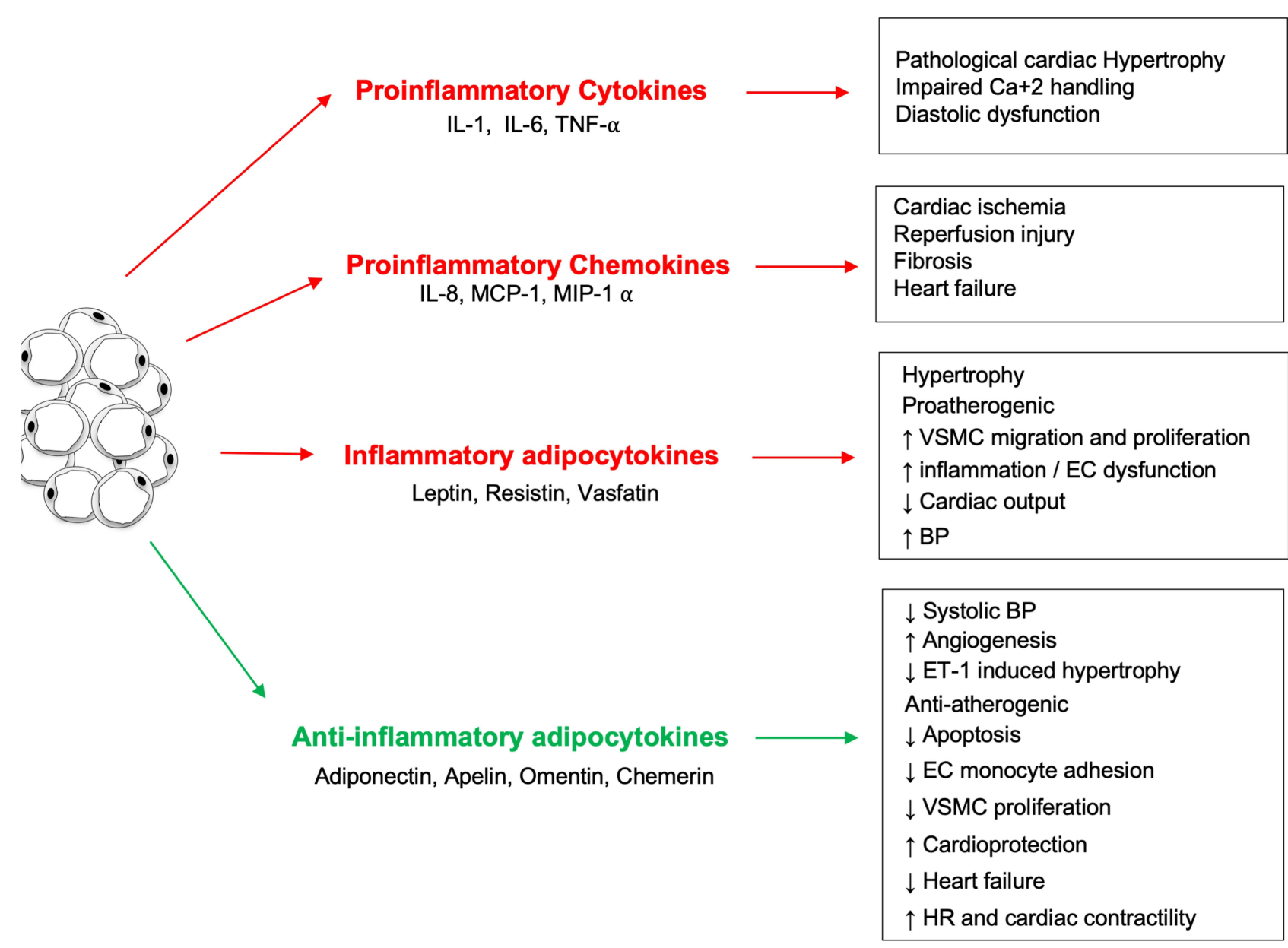

Figure I The inflammatory and anti-inflammatory effects of the different adipocytokines produced by white adipose tissue.

signaling domain and is the most prevalent isoform in the hypothalamus. ${ }^{35}$ It is involved in energy homeostasis and regulates the activity of the secretory organs.

Even though leptin is not a classical cytokine, several immune cells, including polymorphonuclear leukocytes, lymphocytes, monocytes, and macrophages, have receptors for leptin and can be modulated by it. ${ }^{36}$ Leptin shows structural similarity to the cytokines of the long-chain helical family, which includes IL-6, IL-11, IL-12, and oncostatin M (OSM); ${ }^{37}$ in addition, most of leptin's proinflammatory actions seem to be mediated by the Ob-Rb receptor, which has structural homology with the members of the class I cytokine receptor (gp130) superfamily, which includes receptors for IL-6, granulocyte colony-stimulating factor (G-CSF), and leukocyte inhibitory factor (LIF). ${ }^{36}$
When leptin binds to the $\mathrm{Ob}-\mathrm{Rb}$ receptor on monocytes and macrophages, it improves phagocytosis by regulating oxidative stress. ${ }^{38}$ It also increases the synthesis of NO and eicosanoids, acts as a chemoattractant, increases the release of cytokines like TNF- $\alpha$, IL-1, IL-1RA, IL-6, and CC-chemokine ligand, and prevents apoptosis. ${ }^{38}$ In studies that used $o b / o b$ mice and $d b / d b$ animal models, mice lacking leptin or with leptin resistance demonstrated numerous pathologies of the immune system. ${ }^{39,40}$

\section{Leptin and the Immune Response}

Obesity causes low-grade chronic inflammation due to modifications in both the innate and adaptive immune systems. ${ }^{41}$ Due to the excessive activation of pro-inflammatory signal transduction pathways in their adipose tissue, overweight and obese individuals generally have 


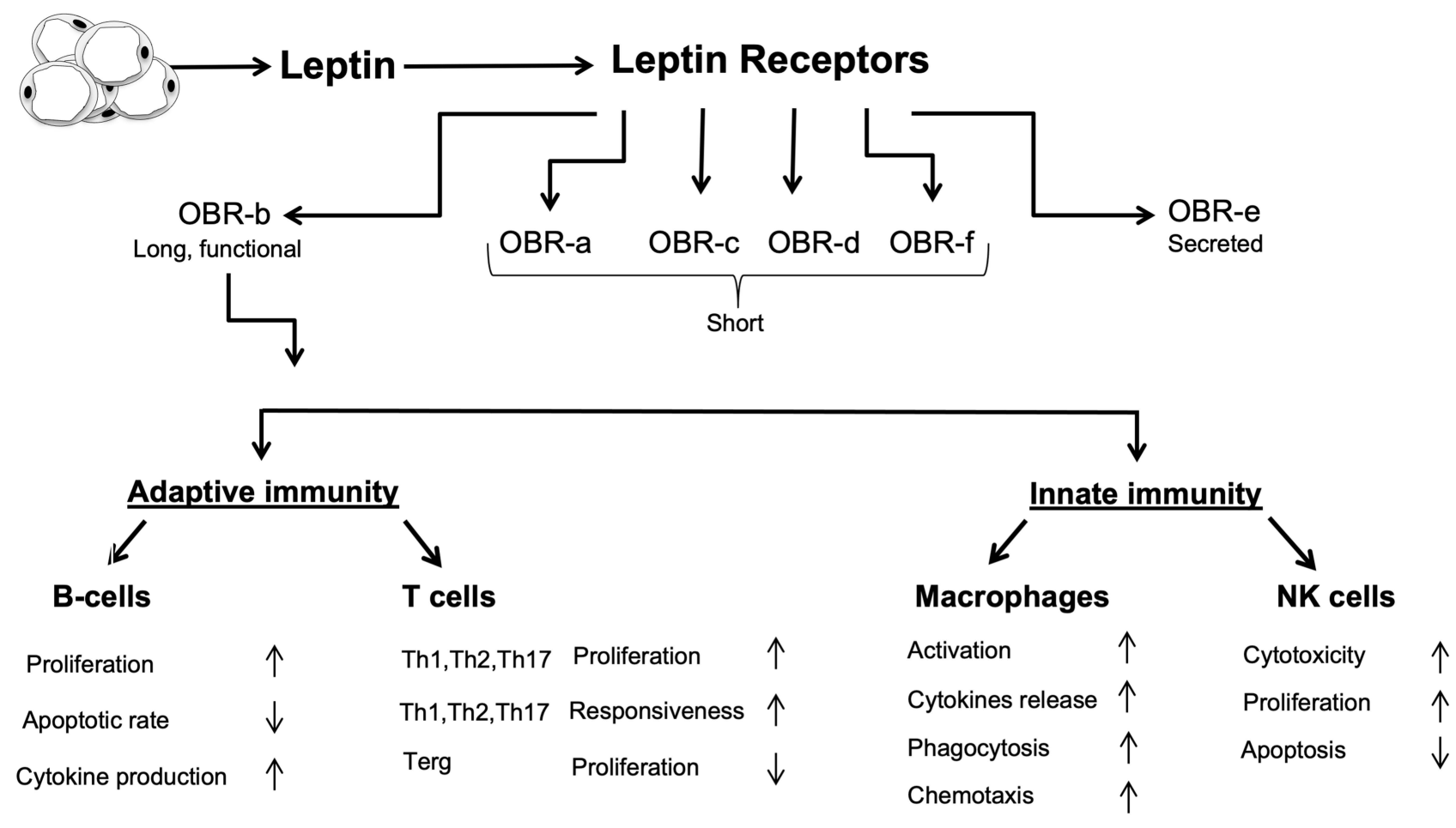

Figure 2 Interactions between leptin and the immune system. Leptin upregulates the formation of different inflammatory proteins through activating both innate and adaptive immunity.

higher levels of the pro-inflammatory cytokines C-reactive protein, IL-6, and TNF- $\alpha$. In turn, inflammatory stimuli, including IL-1 $\beta$, IL-6, lipopolysaccharide, and TNF- $\alpha$, induce the production of leptin, whose plasma levels have been shown to be markedly increased during inflammation, acute infection, and sepsis. ${ }^{42,43}$ The leptin receptor has been found in both innate and adaptive immunity cells, including macrophages, neutrophils, natural killer (NK) cells, dendritic cells, and lymphocytes. ${ }^{36}$ In turn, leptin modulates the immune response and inflammation in several ways.

In the innate immune system, leptin exerts various actions. It stimulates monocytes to release pro-inflammatory cytokines, such as IL-6, IL-12, and TNF- $\alpha$, and upregulates the expression of cell surface markers involved in the activation of resting monocytes. ${ }^{36}$ Leptin also promotes the proliferation and differentiation of monocytes into macrophages but exerts an anti-apoptotic effect in macrophages by stimulating phagocytosis. ${ }^{44}$ Notably, neutrophil activation in response to leptin requires $\mathrm{TNF}-\alpha$ release from monocytes. ${ }^{45}$

In the adaptive immune system, leptin induces the differentiation of $\mathrm{CD}^{+}$cells into IL-17-secreting Th17 cells, while inhibiting the formation of $\mathrm{CD}^{+} \mathrm{CD} 25^{+} \mathrm{T}_{\text {reg }}$ cells and stress-induced $\mathrm{T}$ cell apoptosis. ${ }^{44}$ Studies have also shown that $f a / f a$ rats, ob/ob mice, and humans with congenital leptin deficiency or leptin receptor mutations have higher infection susceptibility, which is associated with low total lymphocyte and circulating $\mathrm{CD}^{+} \mathrm{T}$ cell levels, thymocyte apoptosis, and a shift towards a Th2 immune response. Administering recombinant leptin to humans with leptin deficiency as well as $o b / o b$ mice significantly increases thymic cellularity and upregulated cytokine secretion by immune cells. ${ }^{46}$ In B cells, leptin exerts pro-inflammatory actions by inducing the secretion of IL-6, IL-10, and TNF- $\alpha{ }^{47}$

\section{Leptin and Cardiovascular Diseases}

In humans, hyperleptinemia is associated with acute cardiovascular events and obesity-related hypertension. ${ }^{48}$ Cardiac hypertrophy occurs in response to a change in load. In conditions like hypertension, the parallel addition of sarcomeres increases the myocyte width, which in turn increases the wall thickness. Hyperleptinemia is observed in patients with left ventricular hypertrophy (LVH), where the myocardium of the left ventricle enlarges. Several factors like hypertension, age, and obesity contribute to LVH. Although its exact role in cardiac hypertrophy is not entirely clear, leptin is believed to maintain the left 
ventricular wall thickness and cellular structure of myocyte. $^{48}$ In the leptin-deficient $o b / o b$ mouse model, leptin repletion has been shown to reverse LVH back to normal, a process that is mediated through the activation of janus kinase (JAK)-dependent signaling. ${ }^{49}$ Hence, leptin or its components in downstream signaling exert an anti-hypertrophic effect on the heart independent of weight loss.

In contrast, in obese people whose leptin levels are significantly increased, this hormone has been shown to be a key factor in the pathogenesis of $\mathrm{LVH}^{50}$ In vitro studies done by exposing neonatal rat ventricular myocytes to a concentration of leptin that represents average leptin levels in obese people showed an increase in cell surface area by $42 \%{ }^{51}$ Inhibitors of ERK $1 / 2$ and p38 have been shown to reduce leptin-induced cardiomyocyte hypertrophy. ${ }^{51}$

In addition, leptin decreases the contractility of cardiomyocytes, possibly by increasing NO production. ${ }^{52,53}$ For instance, acute infusion of leptin in isolated rat ventricular myocytes increases the activity of NO and decreases cardiac contractility. ${ }^{54}$ With leptin, NO production was increased and intracellular calcium transients were reduced. $^{55}$ The spatial containment of different NO isoforms within separate subcellular compartments of the cardiac myocyte allows NO signals to have independent effects on cardiac phenotype and contractile response. ${ }^{56}$

To better understand myocardial dysfunction in obesity, the $\beta$-adrenergic response to leptin in cardiomyocytes provides significant insight. Cardiomyocyte contractility is directly depressed by leptin-induced NO increase, an important aspect to consider in obesity. Leptin resistance, an important characteristic of obesity, attenuates the $\beta$-adrenergic response. $^{57}$ In the $\mathrm{H} 9 \mathrm{c} 2$ cardiac cell line, 30-minute leptin therapy showed a greater basal and catecholamine-stimulated adenylate cyclase activity, but a reduced adenylate cyclase activity was seen after the 18-hour treatment. ${ }^{58}$ Therefore, leptin deficiency attenuates the $\beta$-adrenergic response, while moderate stimulation of leptin can improve the contractile response.

Moreover, leptin has been shown to shift myocardial metabolism towards fatty acid utilization. ${ }^{59}$ ATP, which sustains the contractile function of the heart, is mainly produced by the oxidation of fatty acids. In isolated working rat hearts, leptin introduction increased fatty acid oxidation and triacylglycerol lipolysis ${ }^{60}$ and myocardial oxygen consumption was increased due to an increase in mitochondrial uncoupling protein activity. ${ }^{60}$ Increased absorption of fatty acids along with reduced oxidation leads to lipotoxicity of cardiomyocytes treated with leptin.

Several actions are exerted by leptin on the vascular system. These include vascular remodeling, hypertrophy, and angiogenesis. ${ }^{61}$ Leptin aids migration, proliferation, and hypertrophy of vascular smooth muscle cells. Increased platelet aggregation can be induced by leptin as well. ${ }^{61}$ Moreover, in studies where mechanical stretch was used to mimic hypertension in the rat portal vein, leptin production and secretion were increased, suggesting that leptin expression is upregulated in the vasculature in hypertension. ${ }^{32,62}$

\section{Molecular Signaling Pathways for Cardiac Hypertrophy Leptin-Dependent Pathways}

Leptin induces cardiac hypertrophy through several pathways. In the next sections, we provide a brief description of the JAK/STAT, MAPK, and Rho pathways that are activated by leptin, which in turn, promote cardiac remodeling and hypertrophy.

Leptin binding to its receptor leads to the dimerization of the receptor and autophosphorylation and subsequent activation of the Janus kinase-2 (JAK2). ${ }^{63}$ Activated JAK2, in turn, phosphorylates Tyr 985, Tyr 1077, and Tyr 1138 residues on OB-Rb. Activated Tyr 1138 and Tyr 1077 recruit and activate signal transducers and activators of transcription 3 and 5 (STAT3 and STAT5) transcriptional factors, respectively, allowing their detachment from the complex and translocation to the nucleus. ${ }^{64}$ This, in turn, promotes the transcription of the genes responsible for the production of leptin anorexigenic peptide, an appetite depressing peptide. ${ }^{65}$ Furthermore, JAK2 activation leads to the phosphorylation of the src homology 2 (SH2) domain of SHP-2, which can activate the MAPK ERK1/2 signaling pathway. ${ }^{66}$ Leptin is also involved in phosphatidylinositol 3 kinase (PI3K) signaling through activation of insulin receptor substrate (IRS). ${ }^{67}$

Regulation of the leptin pathway involves protein tyrosine phosphatase 1B (PTP1B), which can dephosphorylate JAK2 and thereby inhibit leptin signaling. ${ }^{68}$ Another negative regulator of this pathway is mediated by STAT3, which induces expression of the suppressors of the cytokine signaling (SOCS3) family members that exert negative feedback on leptin signaling via binding to Tyr 985 and specific sites on the Ob-Rb/JAK complex. ${ }^{69}$

The MAPK pathway is mediated by ERK and p38 family members. This pathway is activated by Ob-Ra 
and Ob-Rb. ERK can be activated either by phosphorylation of Tyr 985 and activation of SHP-2 or independently of tyrosine phosphorylation, where JAK2 couples with the SH2 domain of SHP-2. ${ }^{31}$ Leptin treatment has been reported to induce phosphorylation of STAT3 and ERK1/ 2 in leptin-deficient $o b / o b$ mice but not in $\mathrm{Ob}-\mathrm{Rb}$-deficient $d b / d b$ mice, ${ }^{70}$ suggesting that $\mathrm{Ob}-\mathrm{Rb}$ is the main signaling receptor or that the activation of ERK1/2 by JAK2 does not significantly occur in cardiac tissues. ${ }^{70}$ p38 MAPK can also be phosphorylated in response to leptin. ${ }^{64}$ The alpha and beta isoforms of $\mathrm{p} 38$ are abundant in the heart. Leptin has been shown to induce hypertrophy in vascular smooth muscle cells and cardiomyocytes through the p38 MAPK pathway. ${ }^{71}$

Studies have shown that the Rho pathway plays an important role in mediating the hypertrophic effect of leptin via a MAPK-dependent mechanism and regulation of actin dynamics. ${ }^{72}$ Inhibiting ROCK and Rho have blocked the activity of ERK1/2 and p38 after leptin treatment in cultured neonatal rat ventricular myocytes, indicating that Rho/ROCK contributes to the phosphorylation of ERK $1 / 2$ and $\mathrm{p} 38 .^{73}$ The same effect on ERK1/2 and p38 activation was observed after disrupting the actin cytoskeleton. ${ }^{74}$ Collectively, leptin can inactivate cofilin, an actin-binding protein, in a Rho/ROCK-dependent mechanism, causing an increase in G-actin and thereby a decrease in the G-actin to F-actin ratio. In turn, MAPK activation leads to hypertrophy and cardiac remodeling. ${ }^{72}$

\section{Leptin-Independent Pathways}

Various signaling pathways are known to be implicated in cardiac hypertrophy. These pathways are complicated and overlappe, but all are associated with an increase in intracellular calcium ion $\left(\mathrm{Ca}^{2+}\right)$ concentration upon stimulation. $^{75}$ Binding of Ang II and endothelin-1 (ET-1) to the cardiomyocytes' cell surface receptors activates phospholipase $\mathrm{C}$ and subsequently generates inositol triphosphate and diacylglycerol, recruiting intracellular $\mathrm{Ca}^{2+}$ and activating protein kinase C. ${ }^{76,77}$ Thus, Ras and MAP kinase pathways are transducers of hypertrophic signals. ${ }^{78}$

Moreover, calcineurin and calmodulin are molecules involved in the molecular mechanisms that induce cardiac hypertrophy. Calcineurin is a calcium-calmodulin-dependent serine/threonine protein phosphatase that activates the transcription factor NFAT. ${ }^{79,80}$ Upon activation, NFAT translocates to the nucleus and activates gene involved in the hypertrophic response in myocytes. ${ }^{81}$ In the beginning, $\mathrm{Ca}^{2+}$ binds to the regulatory subunit of calcineurin and calmodulin, activating the calcineurin phosphatase activity. NFAT is then dephosphorylated and subsequently activated, rapidly localizing into the nucleus where it binds to GATA $-4^{82}$ leading to hypertrophy-related gene expression. ${ }^{83,84}$ Overexpression of calcineurin and NFAT in mice cardiomyocytes has been shown to lead to severe hypertrophy and subsequent heart failure. ${ }^{85}$

Chronic mechanical stretch (mimicking hypertension) increases calcium levels inside the cell, thereby increasing calcineurin activation and the sequence of events leading to hypertrophy. ${ }^{86}$ To illustrate that calcineurin is a crucial hypertrophic transducer in cardiomyocytes, several studies have used Cyclosporin A (CsA) or FK506, immunosuppressants and known inhibitors for calcineurin, ${ }^{87}$ in their hypertrophic experimental models. ${ }^{88,89}$ Interestingly, various in vitro and in vivo studies demonstrated that calcineurin contributes to hypertrophy in cardiomyocytes. ${ }^{90-92}$ However, more recent studies that used calcineurin inhibitory agents failed to find a significant inhibition of cardiac hypertrophy in vitro. ${ }^{93-95}$

Indeed, research has shown that CsA and FK506 may have undesirable effects that affect the specificity of calcineurin inhibition. High doses of CsA can alter sarcoplasmic reticulum $\mathrm{Ca}^{2+}$ release through different direct and indirect mechanisms. ${ }^{96,97}$ CsA introduction can also inhibit the $\mathrm{Na}^{+}, \mathrm{K}^{+}$-ATPase, resulting in neurotoxicity and nephrotoxicity, and subsequent increase in blood pressure (mechanical stretch). ${ }^{98}$ To overcome this issue, it has been suggested that calcineurin could be genetically inhibited in different ways (reviewed in Table 1). A recent novel study demonstrated the effect of calcineurin inhibition by CUnatriuretic peptides (CU-NP) on cardiac cell hypertrophy. ${ }^{99}$ Neonatal rat myocytes treated with Ang II, PE, and ET-1 in the presence of CU-NP exhibited an attenuation of calcineurin activation and thus inhibition of NFAT translocation to the nucleus and hypertrophy induction. ${ }^{99}$ Table 1 highlights potential methods for calcineurin genetic inhibition. Combined together, these methods emphasize the important role of calcineurin as a transducer of cardiac hypertrophy.

\section{Adiponectin and the Cardiovascular System}

Adiponectin, an anti-inflammatory adipokine (Figure 3) also termed ACRP30, AdipoQ, apM1, and gelatin-binding protein (GBP), is a $30 \mathrm{kDa}$ protein that is produced by adipocytes. Present abundantly, adiponectin accounts for 
Table I Potential Methods for Calcineurin Genetic Inhibition

\begin{tabular}{|l|l|}
\hline Calcineurin Genetic Inhibition Method & Reference(s) \\
\hline $\begin{array}{l}\text { Overexpression of the inhibitory domain of the two } \\
\text { endogenous inhibitors of calcineurin, AKAP79 and }\end{array}$ & {$[100]$} \\
Cain: & \\
AKAP79 is a scaffolding protein that binds to \\
calcineurin, while Cain has a C-terminal domain that \\
non-competitively inhibits calcineurin activity. Using \\
a recombinant adenoviral process to infect rat \\
cardiomyocytes, it has been shown that the calcineurin \\
inhibitory domains from both Cain or AKAP79 inhibit \\
hypertrophy after Ang II and PE infusion.
\end{tabular}

$0.01 \%$ of total plasma proteins and functions in energy metabolism, vascular physiology, and inflammation. ${ }^{104}$ The gene that encodes adiponectin is present on chromosome $3 \mathrm{q} 27$ and consists of three exons and two introns. ${ }^{105}$ Adiponectin circulates in the body at high concentrations but its levels are lowered in obese individuals compared to lean individuals. ${ }^{106}$ The primary sequence of the adiponectin protein is homologous to complement protein $\mathrm{Clq}$ and has structural homology to tumor necrosis factor- $\alpha$ $(\mathrm{TNF}-\alpha){ }^{107}$

Adiponectin consists of three domains which include a signal sequence at the $\mathrm{N}$ terminus, a globular domain at the $\mathrm{C}$ terminus, and a collagen-like domain. ${ }^{31}$ This protein can form a wide range of multimer complexes with these three domains. In the circulation, adiponectin exists in three major oligomeric multimers: A high molecular weight (HMW) multimer of 12-18 monomers, a middle molecular weight hexamer (MMW), and low molecular weight (LMW) trimer. ${ }^{108}$
Adiponectin receptors are mainly AdipoR1, AdipoR2, and T-cadherin. When AdipoR1 and AdipoR2 genes were deleted from different mice models, adiponectin's actions became defective, indicating the importance of AdipoR1 and AdipoR2 in mediating adiponectin signaling. ${ }^{109}$ AdipoR1 is expressed highly in the heart compared to AdipoR2. ${ }^{110} 5^{\prime}$ adenosine monophosphate-activated protein kinase (AMPK) and peroxisome proliferator-activated receptor (PPAR) signaling are two major targets of adiponectin signaling. AdipoR1 deletion has resulted in the blocking of adiponectin mediated phosphorylation of AMPK, while AdipoR2 gene deletion has resulted in increased adiposity and glucose intolerance. ${ }^{111}$ T-cadherin is a surface molecule expressed in cardiomyocytes, vascular smooth muscle cells, and endothelial cells. It regulates their proliferation, migration, and survival. ${ }^{112}$

The role of adiponectin in the pathogenesis of cardiovascular diseases is unclear. A correlation between low adiponectin levels and cardiovascular diseases has been reported. ${ }^{113,114}$ The association of adiponectin in the development of cardiovascular disease is still controversial, and it appears that low levels of adiponectin are not a reliable marker for cardiovascular disease. However, cardiac remodeling has been shown to be influenced by adiponectin, which functions to suppress cardiac growth. ${ }^{115}$ Adiponectin attenuates cardiac hypertrophy in response to pressure overload in adiponectin-knockout, wild, and diabetic $d b / d b$ mice. ${ }^{116}$

Adiponectin has been shown to exert a protective action against myocardial ischemia-reperfusion injury, a process that is mediated by its ability to activate cyclooxygenase-2 (COX-2) in cardiac cells. ${ }^{116}$ When adiponectin binds to T-cadherin, it leads to the attenuation of ROSproduction, TNF- $\alpha$ levels, and AMPK and COX-2 activation. $^{108}$ Thus, by activating the AMPK-mediated anti-apoptotic actions and COX-2 mediated anti-inflammatory actions, adiponectin protects the ischemic heart from injury.

In addition to its anti-inflammatory properties, adiponectin exerts protective actions against cardiac overloadinduced hypertrophy. ${ }^{28}$ Adiponectin has been shown to attenuate overload-induced and adrenergically-induced cardiomyocyte hypertrophy in mice by inhibiting hypertrophic signaling pathways via AMPK. ${ }^{4}$ Therefore, the downregulated levels of this adipokine in obesity are linked to increased cardiac risk in at least 2 ways: Myocardial insult and inflammation-induced cardiovascular insufficiency. 


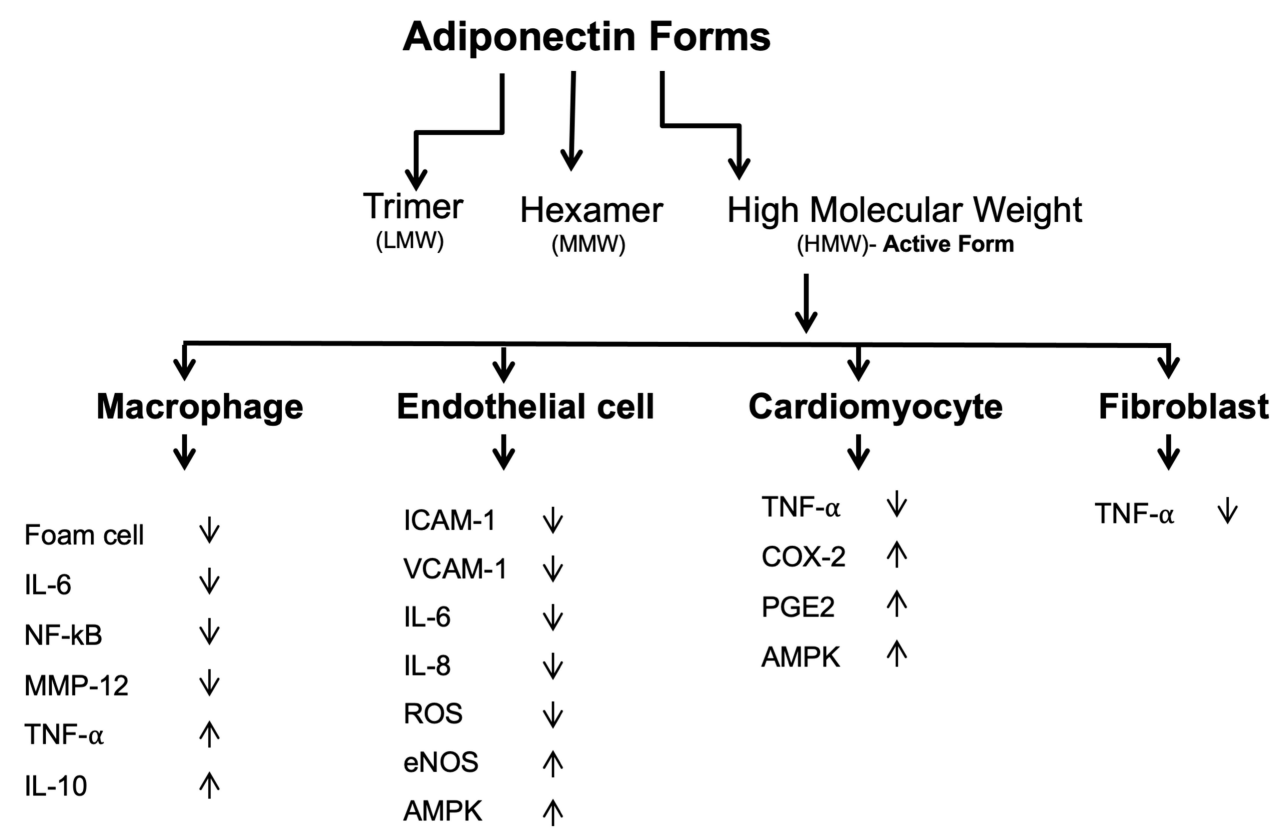

Figure 3 Anti-inflammatory properties of adiponectin. Adiponectin affects several tissues and promotes anti-inflammatory actions by several mechanisms.

Furthermore, adiponectin acts on the vascular system and exerts protective effects in various vascular disorders, such as endothelial dysfunction. ${ }^{117}$ Adiponectin also protects against the harmful vascular remodeling that occurs in response to excessive mechanical stretch induced by hypertension. ${ }^{32}$ Mechanical stretch activates ERK1/2 signaling, increases ROS formation, and induces GATA-4 nuclear translocation in vascular smooth muscle cells, whereas exogenous adiponectin at physiological concentrations inhibits all of these effects in mechanically stretched vessels. ${ }^{32}$ Moreover, exogenous adiponectin has been shown to activate the protective LKB1-AMPK-eNOS signaling axis, which in turn, inhibits hypertensioninduced hypertrophy. ${ }^{32,118,119}$

\section{Autophagy}

Autophagy, a catabolic process that is vastly conserved in all eukaryotes and mammals, ${ }^{120}$ is prompted by one of two processes. The first occurs via physiological processes such as the intracellular accumulation of proteins and organelles that would consequently be degraded into reusable, biologically active monomers like amino acids; ${ }^{120}$ the second process occurs via pathological triggers like starvation, cellular stress, and ROS. ${ }^{121}$ The process of autophagy is essential for organism survival. Pyo et al report that transgenic mice overexpressing autophagyrelated gene 5 (Atg5), an essential protein for the formation of autophagosomes, have a median life span increase by $17 \%$ in addition to their anti-aging phenotypes, which include enhanced leanness, increased insulin sensitivity, and improved motor function. ${ }^{122}$ Concurrently, Yoshii et al report that a deficiency in $\operatorname{Atg} 5$ is lethal. ${ }^{123}$

Autophagy is categorized into three types: Macroautophagy, microautophagy, and chaperonemediated autophagy (CMA). ${ }^{124}$ Macroautophagy is considered the chief pathway for the lysis of large portions of the cytoplasm and cellular contents, such as long-lived proteins, aggregated proteins, damaged organelles, and intracellular pathogens. ${ }^{125}$ This process is initiated by the nucleation and expansion of the double-membraned structure, known as the phagophore, followed by the fusion of lysosomes, membrane-bound cell organelles that contains digestive enzymes, eventually leading to the formation of autophagolysosomes. ${ }^{124}$ Microautophagy is the process by which lysosomes digest small quantities of cytosolic substrates; this could be induced by nitrogen starvation or rapamycin via regulatory signaling complex pathways. ${ }^{124}$ Additionally, the process is initiated by autophagic tubesmediated direct engulfment of cytoplasmic materials and involves both invagination and vesicle scission into the lumen. ${ }^{126}$ On the other hand, CMAis initiated following prolonged physiological stress and is mediated through heat shock cognate protein. ${ }^{124}$ Intriguingly, CMA is a uniquely selective mechanism; proteins that are targeted through this pathway are individually tagged through a recognition motif in their amino acid sequences. This 
ensures efficient and specific degradation of damaged or abnormal proteins. ${ }^{127}$

\section{Autophagy and Cardiac Remodeling}

A variety of physiological, such as exercise and pregnancy, and pathological, including hypertension, valvular heart disease, and myocardial infarction, stimuli could trigger cardiac compensatory mechanisms. ${ }^{128}$ Cardiac modulation in terms of chambers' volume, systolic contraction, diastolic relaxation, heart rate, and muscle mass are common in response to environmental stimulation. ${ }^{128}$ In pathological cases, cardiac remodeling begins with the compensatory mechanism of increasing cardiac overload. ${ }^{128}$ Nonetheless, persistent pathological stimuli consequently induce systolic dysfunction and heart failure. ${ }^{128}$

Autophagy is thought to be one of the main mechanisms controlling the cardiac hypertrophic response. ${ }^{129}$ Although it seems counterintuitive, the involvement of autophagy, a degradation mechanism, in myocyte proliferation and hypertrophic remodeling is attributed to the complex nature of cardiac myocytes. This warrants more than protein synthesis to extend to the disassembling and remodeling of existing cellular elements throughout the process of cardiac remodeling. ${ }^{128}$ In fact, a growing body of evidence in both human heart failure and diseased animal models supports the involvement of the lysosomal pathway in the pathogenesis of heart disease; ${ }^{129}$ indeed, augmented cardiac hypertrophy was found to be associated with autophagy. ${ }^{129}$

To elaborate on the involvement of autophagy in cardiac remodeling, it is crucial to differentiate between adaptive, which is vital for cellular homeostasis, and maladaptive, that is associated with sustained stimuli. ${ }^{128}$ In this review, we illustrate the different maladaptive autophagy signaling pathways in cardiac hypertrophy. Taking into account the minute capacity of cardiac myocytes to undergo cell proliferation, hypertrophy is, therefore, their only method of cellular growth in response to various stimuli. Cardiac hypertrophy is originally initiated as an adaptive mechanism in response to elevated cardiac wall tension and to increase cardiac output. ${ }^{130}$ For instance, Yamaguchi et al report that inducing transient pressure overload through a thoracic transverse aortic constriction (TAC) in wild-type mice leads to cardiac hypertrophy without resulting in cardiac dysfunction or fibrosis. ${ }^{131}$ To illustrate the role autophagy plays in the described case, the expression of LC3, a soluble protein that is recruited to the autophagosomal membrane and is reflective of starvation-induced autophagic activity, was determined using immunoblotting. The study reports a significant decrease in LC3 expression in TAC-induced hypertrophied hearts at 1-week post-surgery as opposed to placebo wildtype hearts and transgenic mice. ${ }^{131}$ Similarly, Dammrich et al report a diminished autophagic response in SpragueDawley rats following supravalvular aortic constriction. ${ }^{132}$

Cardiac hypertrophy is a multi-phased process; during the compensatory hypertrophic response, autophagy is downregulated. The noted decrease in autophagy leads to the accumulation of ROS and harmful proteins. ${ }^{133}$ In the case of a sustained stimulus, such as continuous exposure to an elevated load, cardiac hypertrophy becomes maladaptive. ${ }^{133}$ This, coupled with the increased accumulation of malfunctional mitochondria and harmful proteins, causes a further increase in ROS generation, thus, inducing cellular necrosis and eventually leading to heart failure. ${ }^{130}$ Concurrently, Nishida et al report an initial downregulation in autophagy 1-week post-surgery in wild-type mouse hearts treated with TAC, as opposed to the observed left ventricular (LV) dilation and cardiac dysfunction associated with an upregulation of autophagy following 4 weeks of surgery in the same animal model. ${ }^{130}$ Additionally, in Atg5-deficient mice, a similar stimulus leads to the development of cardiac hypertrophy coupled with LV dilatation and cardiac dysfunction 1-week post surgery. ${ }^{130}$ This emphasizes the role that autophagy upregulation plays in the transitioning from hypertrophy to heart failure.

The mechanism by which autophagy leads to heart failure is yet to be fully illustrated. Nonetheless, studies have shown that the accumulated malfunctional mitochondria increase the generation of ROS and decrease ATP production. ${ }^{134}$ This, in turn, triggers energy sensor AMPK and inhibits mammalian target of rapamycin (mTOR), permitting the activation of Unc-51-like kinase (ULK1). ${ }^{135}$ The formation of Atg1/ULK1 and Class III phosphatidylinositol 3-kinase (PI3K III)/Beclin1 is crucial in the development of the phagophore. The elongation and maturation process of the phagophore is facilitated through two ubiquitin-like conjugation systems; the first involves Atg12-Atg5-conjugate which facilitates localization, while the second involves conjugation of phosphatidylethanolamine (PE) to microtubule-associated protein 1 light chain 3 (LC3)/Atg8, leading to the formation of autophagosomeassociated form LC3-III and eventually forming the autolysosomes. ${ }^{136}$ The described pathway leads to the upregulation of autophagy in heart failure. ${ }^{134}$ Moreover, 
Nishida et al and Miyata et al have reported similar findings in the myocardium caused by dilated cardiomyopathy, valvular disease, and ischemic heart disease ${ }^{130}$ and in animal models such as UM-7.1 cardiomyopathic hamsters, ${ }^{137}$ respectively.

\section{Regulation of Autophagy by Inflammatory Cytokines}

As pointed above, this review focuses on the pro-inflammatory cytokine leptin and anti-inflammatory adiponectin. In general, Th1 cytokines, such as IL-1, IL-2, IL-6, interferon gamma (IFN- $\gamma)$, transforming growth factor beta (TGF- $\beta$ ), and TNF- $\alpha$, induce autophagy. Conversely, the classical Th2 cytokines, including IL-4, IL-10 and IL-13, generally inhibit autophagy. ${ }^{138}$

IFN- $\gamma$-induced activation of macrophages increases the maturation of mycobacteria-containing phagosomes and stimulates autophagy in an Irgm1/IRGM-dependent manner, leading to increased intracellular killing of pathogens. ${ }^{139}$ However, phagosome maturation by IFN- $\gamma$ can be abrogated by TNF blockers, suggesting the involvement of TNF- $\alpha$ in IFN- $\gamma$-induced phagosome maturation and autophagy. Interestingly, TNF- $\alpha$ involvement in autophagy induction has also been shown in various cell types; however, the actions and mechanisms differ between the different cell types. ${ }^{138}$ TNF- $\alpha$ can also stimulate autophagy via the ERK1/2 pathway. ${ }^{140}$ Nuclear factor kappalight-chain-enhancer of activated B cells $(\mathrm{NF}-\kappa \mathrm{B})$ has been shown to inhibit TNF- $\alpha$-induced autophagy, a process that is dependent on ROS generation. ${ }^{141}$

TGF- $\beta$ induces the formation of autophagosomes and increases the expression of autophagic mRNA, including Atg5 and Atg7. ${ }^{142}$ However, both CC chemokine CCL2 (monocyte chemoattractant protein-1) and IL-6 can stimulate autophagy and upregulate anti-apoptotic proteins. ${ }^{138}$ In addition, IL-1 has been shown to stimulate autophagy, ${ }^{143}$ whereas insulin-like growth factor- $1^{144}$ and fibroblast growth factor $2^{145}$ both exert inhibitory effects on autophagy. However, the detailed mechanisms still need to be elucidated.

On the other hand, Th2 cytokines have been shown to inhibit starvation- or inflammatory stimulation-induced autophagy through different pathways. ${ }^{138}$ Inhibition of starvation-induced autophagy has been shown to occur via the Akt pathway, whereas inhibition of IFN- $\gamma$ or rapamycin-induced autophagy occurs through the STAT signaling pathway. ${ }^{138,146}$

\section{Pro-Inflammatory Leptin and Autophagy}

Few studies have discussed the relationship between leptin and autophagy. For instance, Malik et al have shown that leptin injections stimulate the expression of LC3 protein and reduce the expression of $\mathrm{p} 62$ protein in the myocardium, as well as in the kidney, skeletal muscle, and liver, indicating the activation of autophagy. ${ }^{147}$ In contrast, the study also reported that mice with leptin receptor deficiency manifested an increase in autophagy in these tissues. ${ }^{147}$ Therefore, this study suggests that any modification in leptin levels may lead to autophagy. ${ }^{147}$ Being a downstream regulator of leptin and an upstream effector of autophagy, ${ }^{148}$ mTOR, a nutrientsensitive protein, is a key player in this mechanism.

A recent study suggested that in cardiac endothelial cells, leptin contributes to autophagy during cardiac hypertrophic remodeling. ${ }^{149}$ In pressure overload-induced hypertrophy, the activation of the Akt/mTOR pathway through leptin receptor inhibited endothelial autophagy and promoted cardiac inflammation, fibrosis, and dysfunction. ${ }^{149}$ Leptin was shown to impair cardiomyocyte contractile function; however, this effect was reduced after inhibition of autophagy using e-methyladenin (3-MA), demonstrating that leptin affects cardiac contractile function through an autophagydependent mechanism. ${ }^{150}$ In addition, Luo et al have shown that leptin reduces contractile function in rat cardiomyocytes by decreasing oxidative stress and inhibiting autophagy. ${ }^{55}$

Leptin induces the formation of autophagosomes, as evidenced by leptin-mediated upregulation in LC3-II, Atg5, and beclin 1 expression and downregulation in p62 expression. ${ }^{151}$ Moreover, it has been shown that peripherally administering recombinant leptin leads to autophagy in peripheral tissues, including the heart, skeletal muscle, and liver. ${ }^{147}$ In addition, pharmacologically inhibiting ROS by tempol has been shown to attenuate leptininduced autophagosome formation, demonstrating a crucial role for ROS in leptin-induced autophagy. ${ }^{150}$

\section{Anti-Inflammatory Adiponectin and Autophagy}

Recently, the regulation of cardiac autophagy has been considered as a crucial mechanistic part of the adiponectin cardioprotective effect. In response to oxidative stress, adiponectin has been shown to inhibit excessive autophagic activity in cardiomyocytes mainly through the ERKmTOR-AMPK signaling pathway. This demonstrates the potential of adiponectin to act as an anti-oxidant in oxidative stress-related cardiovascular diseases including hypertension-mediated heart failure. ${ }^{152}$ An important role for adiponectin was also reported in high-fat diet-induced 
obesity and cardiac pathology. Deficiency in adiponectin enhanced high-fat diet-induced obesity, cardiac hypertrophy, and contractile dysfunction, possibly through AMPK/ mTOR-dependent reduction in myocardial autophagy. ${ }^{153}$ Moreover, adiponectin deficiency has been shown to promote Ang II-induced cardiac inflammation and fibrosis and reduce macrophage autophagy in cardiac tissues. ${ }^{154}$

Research has shown that in response to pressure overload, aged mice with adiponectin deficiency exhibit reduced cardiac autophagy and increased susceptibility to cardiac dysfunction. ${ }^{155}$ Furthermore, adiponectin directly enhances autophagy flux in cardiac myoblasts. ${ }^{155}$ Collectively, these data indicate that adiponectin may protect against the development of cardiac dysfunction likely through inducing cardiac autophagy, which is important in preserving normal heart function in response to stress or aging. ${ }^{155}$ Induction of autophagy is involved in many biological processes regulated by both leptin and adiponectin, although the mechanisms by which these adipokines modulate autophagy are not well defined.

\section{Conclusion}

Due to the increased risk of cardiovascular disease development in obesity, there is recently a great interest in identifying new mechanisms that govern the cardiovascular response in diseases related to obesity. The mechanisms by which leptin and adiponectin contribute to cardiovascular diseases are multifactorial in nature. For instance, leptin mediated-activation of JAK/STAT, MAPK, and Rho pathways was found to initiate and promote a complex process involving cardiomyocyte proliferation, fibrosis, vascular rarefaction, electrophysiological changes, and inflammation, eventually leading to cardiac remodeling and hypertrophy. Conversely, the role of adiponectin in the pathogenesis of cardiovascular diseases is yet to be fully elucidated. Adiponectin was reported to possess cardio-protective properties through the activation of AMPK-mediated anti-apoptotic actions and COX-2 mediated anti-inflammatory actions. Equally, autophagic activity is crucial in maintaining cardiovascular balance and function. Alterations in autophagic flux in response to leptin and adiponectin occur in many types of heart disorders, and autophagic activity seems to be essential in maintaining cardiovascular balance and function. Changes in autophagic flux, whether in excessive or inadequate levels, may cause cardiac dysfunction. Thus, fully elucidating the mechanisms through which leptin and adiponectin exert their actions on autophagy and determining their effect on the cardiovascular system would be pivotal in the identification of new therapeutic targets for the treatment of various cardiovascular diseases.

\section{Funding}

This review was made possible by Qatar University grants (QUST-1-CMED-2021-6 QUST-1-CMED-2021-7) and award UREP27-050-3-020 from Qatar National Research Fund (a member of Qatar Foundation) to AZ and NPRP13s-0213-200352 to LD.

\section{Disclosure}

The authors report no conflicts of interest for this work and have no affiliations with or involvement in any organization or entity with any financial interest or non-financial interest in the materials discussed in this paper.

\section{References}

1. Ruan Y, Guo Y, Zheng Y, et al. Cardiovascular disease (CVD) and associated risk factors among older adults in six low-and middle-income countries: results from SAGE wave 1. BMC Public Health. 2018;18(1):778. doi:10.1186/s12889-018-5653-9

2. Kannan A, Janardhanan R. Hypertension as a risk factor for heart failure. Curr Hypertens Rep. 2014;16(7):447. doi:10.1007/s119 06-014-0447-7

3. Wu J, Thabet SR, Kirabo A, et al. Inflammation and mechanical stretch promote aortic stiffening in hypertension through activation of p38 mitogen-activated protein kinase. Circ Res. 2014;114 (4):616-625. doi:10.1161/CIRCRESAHA.114.302157

4. Ghantous CM, Farhat R, Djouhri L, et al. Molecular mechanisms of adiponectin-induced attenuation of mechanical stretch-mediated vascular remodeling. Oxid Med Cell Longev. 2020;2020:6425782. doi:10.1155/2020/6425782

5. Lyon RC, Zanella F, Omens JH, Sheikh F. Mechanotransduction in cardiac hypertrophy and failure. Circ Res. 2015;116 (8):1462-1476. doi:10.1161/CIRCRESAHA.116.304937

6. Maillet M, Van Berlo JH, Molkentin JD. Molecular basis of physiological heart growth: fundamental concepts and new players. Nat Rev Mol Cell Biol. 2013;14(1):38. doi:10.1038/ nrm3495

7. Andrade-Oliveira V, Camara NO, Moraes-Vieira PM. Adipokines as drug targets in diabetes and underlying disturbances. J Diabetes Res. 2015;2015:681612. doi:10.1155/2015/681612

8. Park PH. Autophagy induction: a critical event for the modulation of cell death/survival and inflammatory responses by adipokines. Arch Pharm Res. 2018;41(11):1062-1073. doi:10.1007/s12272018-1082-7

9. Nemchenko A, Chiong M, Turer A, Lavandero S, Hill JA. Autophagy as a therapeutic target in cardiovascular disease. J Mol Cell Cardiol. 2011;51(4):584-593. doi:10.1016/j.yjmcc.20 11.06 .010

10. Geng J, Baba M, Nair U, Klionsky DJ. Quantitative analysis of autophagy-related protein stoichiometry by fluorescence microscopy. J Cell Biol. 2008;182(1):129-140. doi:10.1083/jcb. 200711112 
11. Roever L, Palandri Chagas AC. Editorial: cardiac remodeling: new insights in physiological and pathological adaptations. Front Physiol. 2017;8:751. doi:10.3389/fphys.2017.00751

12. Nakamura M, Sadoshima J. Mechanisms of physiological and pathological cardiac hypertrophy. Nat Rev Cardiol. 2018;15 (7):387-407.

13. Kehat I, Molkentin JD. Molecular pathways underlying cardiac remodeling during pathophysiological stimulation. Circulation. 2010;122 (25):2727-2735. doi:10.1161/CIRCULATIONAHA.110.942268

14. Sayer G, Bhat G. The renin-angiotensin-aldosterone system and heart failure. Cardiol Clin. 2014;32(1):21-32. doi:10.1016/j. ccl.2013.09.002

15. Rababa'h AM, Guillory AN, Mustafa R, Hijjawi T. Oxidative stress and cardiac remodeling: an updated edge. Curr Cardiol Rev. 2018;14(1):53-59. doi:10.2174/1573403X14666180111145207

16. Wang $C$, Wang $X$. The interplay between autophagy and the ubiquitin-proteasome system in cardiac proteotoxicity. Biochim Biophys Acta. 2015;1852(2):188-194. doi:10.1016/j.bbadis.20 14.07.028

17. Cao DJ, Gillette TG, Hill JA. Cardiomyocyte autophagy: remodeling, repairing, and reconstructing the heart. Curr Hypertens Rep. 2009;11(6):406-411. doi:10.1007/s11906-009-0070-1

18. Azevedo PS, Polegato BF, Minicucci MF, Paiva SAR, Zornoff LAM. Cardiac remodeling: concepts, clinical impact, pathophysiological mechanisms and pharmacologic treatment. Arq Bras Cardiol. 2016;106(1):62-69.

19. Leask A. Getting to the heart of the matter: new insights into cardiac fibrosis. Circ Res. 2015;116(7):1269-1276. doi:10.1161/ CIRCRESAHA.116.305381

20. Gradman AH, Alfayoumi F. From left ventricular hypertrophy to congestive heart failure: management of hypertensive heart disease. Prog Cardiovasc Dis. 2006;48(5):326-341. doi:10.1016/ j.pcad.2006.02.001

21. Force T, Rosenzweig A, Choukroun G, Hajjar R. Calcineurin inhibitors and cardiac hypertrophy. Lancet. 1999;353 (9161):1290-1292. doi:10.1016/S0140-6736(99)90016-8

22. Doggrell SA, Brown L. Rat models of hypertension, cardiac hypertrophy and failure. Cardiovasc Res. 1998;39(1):89-105. doi:10.1016/S0008-6363(98)00076-5

23. Drazner $\mathrm{MH}$. The transition from hypertrophy to failure: how certain are we? Am Heart Assoc. 2005;112:936-938. doi:10.1161/CIRCULATIONAHA.105.558734

24. Francis GS. Pathophysiology of chronic heart failure. Am J Med. 2001;110(7):37-46. doi:10.1016/S0002-9343(98)00385-4

25. Fuster JJ, Ouchi N, Gokce N, Walsh K. Obesity-induced changes in adipose tissue microenvironment and their impact on cardiovascular disease. Circ Res. 2016;118(11):1786-1807. doi:10.11 61/CIRCRESAHA.115.306885

26. Ouchi N, Kihara S, Funahashi T, et al. Reciprocal association of C-Reactive protein with adiponectin in blood stream and adipose tissue. Circulation. 2003;107(5):671-674. doi:10.1161/01.CIR. 0000055188.83694.B3

27. Farkhondeh T, Llorens S, Pourbagher-Shahri AM, et al. An overview of the role of adipokines in cardiometabolic diseases. Molecules. 2020;25:21. doi:10.3390/molecules25215218

28. Mattu HS, Randeva HS. Role of adipokines in cardiovascular disease. J Endocrinol. 2013;216(1):T17-T36. doi:10.1530/JOE-12-0232

29. Vlasova M, Purhonen AK, Jarvelin MR, Rodilla E, Pascual J, Herzig KH. Role of adipokines in obesity-associated hypertension. Acta Physiologica. 2010;200(2):107-127. doi:10.11 11/j.1748-1716.2010.02171.x

30. Zhang Y, Proenca R, Maffei M, Barone M, Leopold L, Friedman JM. Positional cloning of the mouse obese gene and its human homologue. Nature. 1994;372(6505):425-432. doi:10.1038/372425a0
31. Friedman JM, Halaas JL. Leptin and the regulation of body weight in mammals. Nature. 1998;395(6704):763-770. doi:10.10 $38 / 27376$

32. Ghantous CM, Kobeissy FH, Soudani N, et al. Mechanical stretch-induced vascular hypertrophy occurs through modulation of leptin synthesis-mediated ROS formation and GATA-4 nuclear translocation. Front Pharmacol. 2015;6:240.

33. Soudani N, Ghantous CM, Farhat Z, Shebaby WN, Zibara K, Zeidan A. Calcineurin/NFAT activation-dependence of leptin synthesis and vascular growth in response to mechanical stretch. Front Physiol. 2016;7:433. doi:10.3389/ fphys.2016.00433

34. Landecho MF, Tuero C, Valenti V, Bilbao I, de la Higuera M, Fruhbeck G. Relevance of leptin and other adipokines in obesity-associated cardiovascular risk. Nutrients. 2019;11:11. doi:10.3390/nu11112664

35. Yadav A, Kataria MA, Saini V, Yadav A. Role of leptin and adiponectin in insulin resistance. Clin Chim Acta. 2013; 417:80-84. doi:10.1016/j.cca.2012.12.007

36. Fernández-Riejos P, Najib S, Santos-Alvarez J, et al. Role of leptin in the activation of immune cells. Mediators Inflamm. 2010;2010:568343. doi:10.1155/2010/568343

37. Cava AL, Matarese G. The weight of leptin in immunity. Nat Rev Immunol. 2004;4(5):371-379. doi:10.1038/nri1350

38. Paz-Filho G, Mastronardi C, Franco CB, Wang KB, Wong ML, Licinio J. Leptin: molecular mechanisms, systemic pro-inflammatory effects, and clinical implications. Arq Bras Endocrinol Metabol. 2012;56(9):597-607. doi:10.1590/S00042730201200090000

39. Chandra RK. Cell-mediated immunity in genetically obese (C57BL/6J ob/ob) mice. Am J Clin Nutr. 1980;33(1):13-16. doi:10.1093/ajcn/33.1.13

40. Mandel MA, Mahmoud AAF. Impairment of cell-mediated immunity in mutation diabetic mice $(\mathrm{db} / \mathrm{db}) . J$ Immunol. 1978;120(4):1375.

41. McLaughlin T, Ackerman SE, Shen L, Engleman E. Role of innate and adaptive immunity in obesity-associated metabolic disease. J Clin Invest. 2017;127(1):5-13. doi:10.1172/JCI88876

42. Makki K, Froguel P, Wolowczuk I. Adipose tissue in obesity-related inflammation and insulin resistance: cells, cytokines, and chemokines. ISRN Inflammation. 2013;2013:139239. doi: $10.1155 / 2013 / 139239$

43. Iikuni N, Lam QLK, Lu L, Matarese G, La Cava A. Leptin and inflammation. Curr Immunol Rev. 2008;4(2):70-79. doi:10.2174/ 157339508784325046

44. Francisco V, Pino J, Campos-Cabaleiro V, et al. Obesity, fat mass and immune system: role for leptin. Front Physiol. 2018;9:640. doi:10.3389/fphys.2018.00640

45. Zarkesh-Esfahani H, Pockley AG, Wu Z, Hellewell PG, Weetman AP, Ross RJ. Leptin indirectly activates human neutrophils via induction of TNF-alpha. J Immunol. 2004;172 (3):1809-1814. doi:10.4049/jimmunol.172.3.1809

46. Poetsch MS, Strano A, Guan K. Role of leptin in cardiovascular diseases. Front Endocrinol (Lausanne). 2020;11:354. doi:10. 3389/fendo.2020.00354

47. Agrawal S, Gollapudi S, Su H, Gupta S. Leptin activates human $B$ cells to secrete TNF- $\alpha$, IL- 6 , and IL-10 via JAK2/STAT3 and p38MAPK/ERK1/2 signaling pathway. J Clin Immunol. 2011;31 (3):472-478. doi:10.1007/s10875-010-9507-1

48. Barouch LA, Berkowitz DE, Harrison RW, O'Donnell CP, Hare JM. Disruption of leptin signaling contributes to cardiac hypertrophy independently of body weight in mice. Circulation. 2003;108(6):754-759. doi:10.1161/01.CIR.0000083716.82622. FD 
49. Tune JD, Considine RV. Effects of leptin on cardiovascular physiology. J Am Soc Hypertens. 2007;1(4):231-241. doi:10. 1016/j.jash.2007.04.001

50. Hall ME, Harmancey R, Stec DE. Lean heart: role of leptin in cardiac hypertrophy and metabolism. World J Cardiol. 2015;7 (9):511-524. doi:10.4330/wjc.v7.i9.511

51. Rajapurohitam V, Gan XT, Kirshenbaum LA, Karmazyn M. The obesity-associated peptide leptin induces hypertrophy in neonatal rat ventricular myocytes. Circ Res. 2003;93(4):277-279. doi:10.1161/01.RES.0000089255.37804.72

52. Chaban R, Buschmann K, Ghazy A, et al. In vitro effect of leptin on human cardiac contractility. J Nutr Sci. 2019;8:e12-e12. doi:10.1017/jns.2019.6

53. Dong F, Zhang X, Ren J. Leptin regulates cardiomyocyte contractile function through endothelin-1 receptor-NADPH oxidase pathway. Hypertension. 2006;47(2):222-229. doi:10.1161/01. HYP.0000198555.51645.f1

54. Nickola MW, Wold LE, Colligan PB, Wang G-J, Samson WK, Ren J. Leptin attenuates cardiac contraction in rat ventricular myocytes. Hypertension. 2000;36(4):501-505. doi:10.1161/01.HYP.36.4.501

55. Luo L-J, Liu Y-P, Yuan X, et al. Leptin attenuates the contractile function of adult rat cardiomyocytes involved in oxidative stress and autophagy. Acta Cardiologica Sinica. 2016;32(6):723-730.

56. Barouch L, Harrison RW, Skaf MW, Rosas GO, Cappola TP, Kobeissi A. Nitric oxide regulates the heart by spatial confinement of nitric oxide synthase isoforms. nature. 2002;416 (6878):337-339. doi:10.1038/416337a

57. Carter S, Caron A, Richard D, Picard F. Role of leptin resistance in the development of obesity in older patients. Clin Interv Aging. 2013;8:829-844.

58. Illiano G, Naviglio S, Pagano M, et al. Leptin affects adenylate cyclase activity in $\mathrm{H} 9 \mathrm{c} 2$ cardiac cell line: effects of short- and long-term exposure. Am J Hypertens. 2002;15(7 Pt 1):638-643. doi:10.1016/S0895-7061(02)02925-4

59. Ma Y, Li J. Metabolic shifts during aging and pathology. Compr Physiol. 2015;5(2):667-686.

60. Atkinson LL, Fischer MA, Lopaschuk GD. Leptin activates cardiac fatty acid oxidation independent of changes in the AMP-activated protein kinase-acetyl-CoA carboxylase-malonylCoA axis. J Biol Chem. 2002;277(33):29424-29430. doi:10.1074/ jbc.M203813200

61. Nakata N, Soejima N, Maruyama I. Leptin promotes aggregation of human platelets via the long form of its receptor. Diabetes. 1999;48:426-429. doi:10.2337/diabetes.48.2.426

62. Zeidan A, Rajapurohitam V, Javadov S, Chakrabarti S, Karmazyn M. Leptin induces vascular smooth muscle cell hypertrophy through angiotensin II- and endothelin-1-dependent mechanisms and mediates stretch-induced hypertrophy. J Pharmacol Exp Thera. 2005; 315:1075-1084. doi:10.1124/jpet.105.091561

63. Ferrao RD, Wallweber HJ, Lupardus PJ. Receptor-mediated dimerization of JAK2 FERM domains is required for JAK2 activation. Elife. 2018;7:e38089. doi:10.7554/eLife.38089

64. Procaccini C, Lourenco EV, Matarese G, La Cava A. Leptin signaling: a key pathway in immune responses. Curr Signal Transduct Ther. 2009;4(1):22-30. doi:10.2174/157436209787048711

65. Sobrino Crespo C, Perianes Cachero A, Puebla Jiménez L, Barrios V, Arilla Ferreiro E. Peptides and food intake. Front Endocrinol (Lausanne). 2014;5:58. doi:10.3389/fendo.2014.00058

66. Chong ZZ, Maiese K. The Src homology 2 domain tyrosine phosphatases SHP-1 and SHP-2: diversified control of cell growth, inflammation, and injury. Histol Histopathol. 2007;22 (11):1251-1267.

67. Thon M, Hosoi T, Ozawa K. Possible integrative actions of leptin and insulin signaling in the hypothalamus targeting energy homeostasis. Front Endocrinol (Lausanne). 2016;7:138. doi:10.3389/fendo.2016.00138
68. Tsou RC, Bence KK. Central regulation of metabolism by protein tyrosine phosphatases. Front Neurosci. 2013;6:192. doi:10.3389/ fnins.2012.00192

69. Mullen M, Gonzalez-Perez RR. Leptin-induced JAK/STAT signaling and cancer growth. Vaccines (Basel). 2016;4(3):26. doi:10.3390/vaccines4030026

70. Buettner C, Pocai A, Muse ED, Etgen AM, Myers MG Jr, Rossetti L. Critical role of STAT3 in leptin's metabolic actions. Cell Metab. 2006;4(1):49-60. doi:10.1016/j.cmet.2006.04.014

71. Yang R, Barouch LA. Leptin signaling and obesity: cardiovascular consequences. Circ Res. 2007;101(6):545-559. doi:10.1161/ CIRCRESAHA.107.156596

72. Zeidan A, Javadov S, Karmazyn M. Essential role of Rho/ ROCK-dependent processes and actin dynamics in mediating leptin-induced hypertrophy in rat neonatal ventricular myocytes. Cardiovasc Res. 2006;72(1):101-111.

73. Zeidan A, Javadov S, Chakrabarti S, Karmazyn M. Leptininduced cardiomyocyte hypertrophy involves selective caveolae and RhoA/ROCK-dependent p38 MAPK translocation to nuclei. Cardiovasc Res. 2007;77(1):64-72. doi:10.1093/cvr/cvm020

74. Hoffman L, Jensen CC, Yoshigi M, Beckerle M. Mechanical signals activate p38 MAPK pathway-dependent reinforcement of actin via mechanosensitive HspB1. Mol Biol Cell. 2017;28 (20):2661-2675. doi:10.1091/mbc.e17-02-0087

75. Fearnley CJ, Roderick HL, Bootman MD. Calcium signaling in cardiac myocytes. Cold Spring Harb Perspect Biol. 2011;3(11): a004242-a004242. doi:10.1101/cshperspect.a004242

76. Sadoshima J, Izumo S. Signal transduction pathways of angiotensin II-induced c-fos gene expression in cardiac myocytes in vitro. Roles of phospholipid-derived second messengers. Circ Res. 1993;73(3):424-438. doi:10.1161/01.RES.73.3.424

77. Zou Y, Komuro I, Yamazaki T, et al. Protein kinase C, but not tyrosine kinases or Ras, plays a critical role in angiotensin II-induced activation of Raf-1 kinase and extracellular signal-regulated protein kinases in cardiac myocytes. $J$ Biol Chem. 1996;271(52):33592-33597. doi:10.1074/jbc.271.52.33 592

78. Thorburn A, Thorburn J, Chen S-Y, et al. HRas-dependent pathways can activate morphological and genetic markers of cardiac muscle cell hypertrophy. J Biol Chem. 1993;268(3):2244-2249. doi:10.1016/S0021-9258(18)53988-0

79. Kudryavtseva O, Aalkjaer C, Matchkov VV. Vascular smooth muscle cell phenotype is defined by $\mathrm{Ca} 2+$-dependent transcription factors. Febs J. 2013;280(21):5488-5499. doi:10.1111/febs.12414

80. Rao A, Luo C, Hogan PG. Transcription factors of the NFAT family: regulation and function. Annu Rev Immunol. 1997;15:707-747. doi:10.1146/annurev.immunol.15.1.707

81. Liu Q, Chen Y, Auger-Messier M, Molkentin JD. Interaction between NFאB and NFAT coordinates cardiac hypertrophy and pathological remodeling. Circ Res. 2012;110(8):1077-1086. doi:10.1161/CIRCRESAHA.111.260729

82. Beals CR, Sheridan CM, Turck CW, Gardner P, Crabtree GR. Nuclear export of NF-ATc enhanced by glycogen synthase kinase-3. Science. 1997;275(5308):1930-1933. doi:10.1126/ science.275.5308.1930

83. Saito T, Fukuzawa J, Osaki J, et al. Roles of calcineurin and calcium/calmodulin-dependent protein kinase II in pressure overload-induced cardiac hypertrophy. $J$ Mol Cell Cardiol. 2003;35(9):1153-1160. doi:10.1016/S0022-2828(03)00234-7

84. Liang Q, Molkentin JD. Redefining the roles of p38 and JNK signaling in cardiac hypertrophy: dichotomy between cultured myocytes and animal models. J Mol Cell Cardiol. 2003;35 (12):1385-1394. doi:10.1016/j.yjmcc.2003.10.001

85. Molkentin JD, Lu J-R, Antos CL, et al. A calcineurin-dependent transcriptional pathway for cardiac hypertrophy. Cell. 1998;93 (2):215-228. doi:10.1016/S0092-8674(00)81573-1 
86. Zhu J, McKeon F. NF-AT activation requires suppression of Crm1-dependent export by calcineurin. Nature. 1999;398 (6724):256. doi:10.1038/18473

87. Hogan PG, Chen L, Nardone J, Rao A. Transcriptional regulation by calcium, calcineurin, and NFAT. Genes Dev. 2003;17 (18):2205-2232. doi:10.1101/gad.1102703

88. Goldspink PH, McKinney RD, Kimball VA, Geenen DL, Buttrick PM. Angiotensin II induced cardiac hypertrophy in vivo is inhibited by cyclosporin A in adult rats. Mol Cell Biochem. 2001;226(1-2):83-88. doi:10.1023/A:1012789819926

89. Shimoyama M, Hayashi D, Zou Y, et al. Calcineurin inhibitor attenuates the development and induces the regression of cardiac hypertrophy in rats with salt-sensitive hypertension. Circulation. 2000;102(16):1996-2004. doi:10.1161/01.CIR.102.16.1996

90. Sussman MA, Lim HW, Gude N, et al. Prevention of cardiac hypertrophy in mice by calcineurin inhibition. Science. 1998;281 (5383):1690-1693. doi:10.1126/science.281.5383.1690

91. Meguro T, Hong C, Asai K, et al. Cyclosporine attenuates pressure-overload hypertrophy in mice while enhancing susceptibility to decompensation and heart failure. Circ Res. 1999;84 (6):735-740. doi:10.1161/01.RES.84.6.735

92. Mende U, Kagen A, Cohen A, Aramburu J, Schoen F, Neer E. Transient cardiac expression of constitutively active Gaq leads to hypertrophy and dilated cardiomyopathy by calcineurin-dependent and independent pathways. Proc Natl Acad Sci. 1998;95 (23):13893-13898. doi:10.1073/pnas.95.23.13893

93. Luo Z, Shyu K-G, Gualberto A, Walsh K. Calcineurin inhibitors and cardiac hypertrophy. Nat Med. 1998;4(10):1092. doi:10.1038/2578

94. Zhang W, Kowal RC, Rusnak F, Sikkink RA, Olson EN, Victor RG. Failure of calcineurin inhibitors to prevent pressure-overload left ventricular hypertrophy in rats. Circ Res. 1999;84(6):722-728. doi:10.1161/01.RES.84.6.722

95. Fatkin D, McConnell BK, Mudd JO, et al. An abnormal Ca 2+ response in mutant sarcomere protein-mediated familial hypertrophic cardiomyopathy. J Clin Invest. 2000;106(11):1351-1359. doi:10.1172/JCI11093

96. Janssen PM, Zeitz O, Keweloh B, et al. Influence of cyclosporine A on contractile function, calcium handling, and energetics in isolated human and rabbit myocardium. Cardiovasc Res. 2000;47 (1):99-107. doi:10.1016/S0008-6363(00)00052-3

97. Park KS, Kim TK, Kim DH. Cyclosporin A treatment alters characteristics of $\mathrm{Ca} 2+$-release channel in cardiac sarcoplasmic reticulum. Am J Physiol-Heart Circulatory Physiol. 1999;276(3): H865-H872. doi:10.1152/ajpheart.1999.276.3.H865

98. Klee CB, Ren H, Wang X. Regulation of the calmodulin-stimulated protein phosphatase, calcineurin. J Biol Chem. 1998;273 (22):13367-13370. doi:10.1074/jbc.273.22.13367

99. Kilić A, Rajapurohitam V, Sandberg SM, et al. A novel chimeric natriuretic peptide reduces cardiomyocyte hypertrophy through the NHE-1-calcineurin pathway. Cardiovasc Res. 2010;88 (3):434-442. doi:10.1093/cvr/cvq254

100. Taigen T, De Windt LJ, Lim HW, Molkentin JD. Targeted inhibition of calcineurin prevents agonist-induced cardiomyocyte hypertrophy. Proc Natl Acad Sci U S A. 2000;97(3):1196-1201. doi:10.1073/pnas.97.3.1196

101. Zou Y, Yao A, Zhu W, et al. Isoproterenol activates extracellular signal-regulated protein kinases in cardiomyocytes through calcineurin. Circulation. 2001;104(1):102-108. doi:10.1161/ hc2601.090987

102. Bueno OF, Brandt EB, Rothenberg ME, Molkentin JD. Defective $T$ cell development and function in calcineurin A beta -deficient mice. Proc Natl Acad Sci USA. 2002;99(14):9398-9403. doi:10. 1073/pnas.152665399
103. Wilkins BJ, Molkentin JD. Calcineurin and cardiac hypertrophy: where have we been? Where are we going? J Physiol. 2002;541 (Pt 1):1-8. doi:10.1113/jphysiol.2002.017129

104. $\mathrm{Gu}$ HF. Biomarkers of adiponectin: plasma protein variation and genomic DNA polymorphisms. Biomark Insights. 2009;4:12 3-133. doi:10.4137/BMI.S3453

105. Ghoshal K, Bhattacharyya M. Adiponectin: probe of the molecular paradigm associating diabetes and obesity. World J Diabetes. 2015;6(1):151-166. doi:10.4239/wjd.v6.i1.151

106. Berk ES, Kovera AJ, Boozer CN, Pi-Sunyer FX, Johnson JA, Albu JB. Adiponectin levels during low- and high-fat eucaloric diets in lean and obese women. Obes Res. 2005;13(9):1566-1571. doi:10.1038/oby.2005.192

107. Anders H, Berg T. ACRP30/adiponectin: an adipokine regulating glucose and lipid metabolism. Trends Endocrinol Metab. 2002;13:84-89.

108. Ghantous CM, Azrak Z, Hanache S, Abou-Kheir W, Zeidan A. Differential role of leptin and adiponectin in cardiovascular system. Int J Endocrinol. 2015;2015:534320. doi:10.1155/2015/534320

109. Yamauchi T, Kadowaki T. Adiponectin receptor as a key player in healthy longevity and obesity-related diseases. Cell Metab. 2013;17(2):185-196. doi:10.1016/j.cmet.2013.01.001

110. Parker-Duffen JL, Nakamura K, Silver M, et al. Divergent roles for adiponectin receptor 1 (AdipoR1) and AdipoR2 in mediating revascularization and metabolic dysfunction in vivo. J Biol Chem. 2014;289(23):16200-16213. doi:10.1074/jbc.M114.548115

111. Kadowaki T, Yamauchi T, Kubota N, Hara K, Ueki K, Tobe K. Adiponectin and adiponectin receptors in insulin resistance, diabetes, and the metabolic syndrome. J Clin Invest. 2006;116 (7):1784-1792. doi:10.1172/JCI29126

112. Resinka TJ, M P, Joshia MB, Kyriakakisa E, Erneb P. Cadherins in cardiovascular disease. J Swiss Soc Infect Dis. 2009;139:0930.

113. Amirzadegan A, Shakarami A, Borumand MA, Davoodi G, Ghaffari-Marandi N, Jalali A. Correlation between plasma adiponectin levels and the presence and severity of coronary artery disease. J Tehran Heart Cent. 2013;8(3):140-145.

114. Kim-Mitsuyama S, Soejima H, Yasuda O, et al. Total adiponectin is associated with incident cardiovascular and renal events in treated hypertensive patients: subanalysis of the ATTEMPT-CVD randomized trial. Sci Rep. 2019;9(1):16589. doi:10.1038/s41598-019-52977-x

115. Hopkins TA, Ouchi N, Shibata R, Walsh K. Adiponectin actions in the cardiovascular system. Cardiovasc Res. 2007;74(1):11-18. doi:10.1016/j.cardiores.2006.10.009

116. Teresa A, Hopkins NO, Shibata R, Walsh K. Adiponectin actions in the cardiovascular system. Cardiovasc Res. 2007;74:11-18.

117. Ebrahimi-Mamaeghani M, Mohammadi S, Arefhosseini SR, Fallah P, Bazi Z. Adiponectin as a potential biomarker of vascular disease. Vasc Health Risk Manag. 2015;11:55-70.

118. Zhang M, Dong Y, Xu J, et al. Thromboxane receptor activates the AMP-activated protein kinase in vascular smooth muscle cells via hydrogen peroxide. Circ Res. 2008;102(3):328-337. doi:10.1161/CIRCRESAHA.107.163253

119. Nour-Eldine W, Ghantous CM, Zibara K, et al. Adiponectin attenuates angiotensin II-induced vascular smooth muscle cell remodeling through nitric oxide and the RhoA/ROCK pathway. Front Pharmacol. 2016;7:86. doi:10.3389/fphar.2016.00086

120. $\mathrm{Li} \mathrm{L}, \mathrm{Xu} \mathrm{J}, \mathrm{He} \mathrm{L}$, et al. The role of autophagy in cardiac hypertrophy. Acta Biochim Biophys Sin (Shanghai). 2016;48 (6):491-500. doi:10.1093/abbs/gmw025

121. Ucar A, Gupta SK, Fiedler J, et al. The miRNA-212/132 family regulates both cardiac hypertrophy and cardiomyocyte autophagy. Nat Commun. 2012;3(1):1078. doi:10.1038/ncomms2090 
122. Pyo J-O, Yoo S-M, Ahn -H-H, et al. Overexpression of Atg5 in mice activates autophagy and extends lifespan. Nat Commun. 2013;4:2300. doi:10.1038/ncomms3300

123. Yoshii SR, Kuma A, Mizushima N. Transgenic rescue of Atg5-null mice from neonatal lethality with neuron-specific expression of ATG5: systemic analysis of adult Atg5-deficient mice. Autophagy. 2017;13 (4):763-764. doi:10.1080/15548627.2017.1280221

124. Khandia R, Dadar M, Munjal A, et al. A comprehensive review of autophagy and its various roles in infectious, non-infectious, and lifestyle diseases: current knowledge and prospects for disease prevention, novel drug design, and therapy. Cells. 2019;8(7):674. doi:10.3390/cells8070674

125. Randow F, Münz C. Autophagy in the regulation of pathogen replication and adaptive immunity. Trends Immunol. 2012;33 (10):475-487. doi:10.1016/j.it.2012.06.003

126. Li WW, Li J, Bao JK. Microautophagy: lesser-known self-eating. Cell Mol Life Sci. 2012;69(7):1125-1136. doi:10.1007/s00018011-0865-5

127. Cuervo AM, Wong E. Chaperone-mediated autophagy: roles in disease and aging. Cell Res. 2014;24(1):92-104. doi:10.1038/ cr.2013.153

128. Rifki OF, Hill JA. Cardiac autophagy: good with the bad. J Cardiovasc Pharmacol. 2012;60(3):248-252. doi:10.1097/ FJC.0b013e3182646cb1

129. Miyamoto S. Autophagy and cardiac aging. Cell Death Differ. 2019;26(4):653-664. doi:10.1038/s41418-019-0286-9

130. Nishida K, Otsu K. Autophagy during cardiac remodeling. J Mol Cell Cardiol. 2016;95:11-18. doi:10.1016/j.yjmcc.2015.12.003

131. Yamaguchi O, Higuchi Y, Hirotani S, et al. Targeted deletion of apoptosis signal-regulating kinase 1 attenuates left ventricular remodeling. Proc Natl Acad Sci. 2003;100(26):15883. doi:10.1073/pnas.2136717100

132. Dammrich J, Pfeifer U. Cardiac hypertrophy in rats after supravalvular aortic constriction. II. Inhibition of cellular autophagy in hypertrophying cardiomyocytes. Virchows Arch B Cell Pathol Incl Mol Pathol. 1983;43(3):287-307. doi:10.1007/BF02932962

133. Osterholt M, Nguyen TD, Schwarzer M, Doenst T. Alterations in mitochondrial function in cardiac hypertrophy and heart failure. Heart Fail Rev. 2013;18(5):645-656. doi:10.1007/s10741-0129346-7

134. Kroemer G, Marino G, Levine B. Autophagy and the integrated stress response. Mol Cell. 2010;40(2):280-293. doi:10.1016/j. molcel.2010.09.023

135. Alers S, Löffler AS, Wesselborg S, Stork B. Role of AMPK-mTOR-Ulk1/2 in the regulation of autophagy: cross talk, shortcuts, and feedbacks. Mol Cell Biol. 2012;32(1):2-11. doi:10.1128/MCB.06159-11

136. Chiu B, Jantuan E, Shen F, Chiu B, Sergi C. Autophagy-inflammasome interplay in heart failure: a systematic review on basics, pathways, and therapeutic perspectives. Ann Clin Lab Sci. 2017;47(3):243-252.

137. Miyata S, Takemura G, Kawase Y, et al. Autophagic cardiomyocyte death in cardiomyopathic hamsters and its prevention by granulocyte colony-stimulating factor. Am J Pathol. 2006;168 (2):386-397. doi:10.2353/ajpath.2006.050137

138. Qian M, Fang X, Wang X. Autophagy and inflammation. Clin Transl Med. 2017;6(1):24. doi:10.1186/s40169-017-0154-5

139. Maphasa RE, Meyer M, Dube A. The macrophage response to mycobacterium tuberculosis and opportunities for autophagy inducing nanomedicines for tuberculosis therapy. Front Cell Infect Microbiol. 2021;10:915. doi:10.3389/fcimb.2020.61 8414
140. Yuan Y, Ding D, Zhang N, et al. TNF- $\alpha$ induces autophagy through ERK1/2 pathway to regulate apoptosis in neonatal necrotizing enterocolitis model cells IEC-6. Cell Cycle. 2018;17 (11):1390-1402. doi:10.1080/15384101.2018.1482150

141. Djavaheri-Mergny M, Amelotti M, Mathieu J, Besançon F, Bauvy C, Codogno P. Regulation of autophagy by NF-kappaB transcription factor and reactives oxygen species. Autophagy. 2007;3(4):390-392. doi:10.4161/auto.4248

142. Ding Y, Choi ME. Regulation of autophagy by TGF- $\beta$ : emerging role in kidney fibrosis. Semin Nephrol. 2014;34(1):62-71. doi:10.1016/j.semnephrol.2013.11.009

143. Khan NM, Ansari MY, Haqqi TM. Sucrose, but not glucose, blocks IL1- $\beta$-induced inflammatory response in human chondrocytes by inducing autophagy via AKT/mTOR pathway. $J$ Cell Biochem. 2017;118(3):629-639. doi:10.1002/jcb.25750

144. Liu ZQ, Zhao S, Fu WQ. Insulin-like growth factor 1 antagonizes lumbar disc degeneration through enhanced autophagy. $\mathrm{Am}$ $J$ Transl Res. 2016;8(10):4346-4353.

145. Wang X, Qi H, Wang Q, et al. FGFR3/fibroblast growth factor receptor 3 inhibits autophagy through decreasing the ATG12-ATG5 conjugate, leading to the delay of cartilage development in achondroplasia. Autophagy. 2015;11(11):1998-2013. doi:10.1080/15548627.2015.1091551

146. Park HJ, Lee SJ, Kim SH, et al. IL-10 inhibits the starvation induced autophagy in macrophages via class I phosphatidylinositol 3-kinase (PI3K) pathway. Mol Immunol. 2011;48(4):720-727. doi:10.1016/j. molimm.2010.10.020

147. Malik SA, Mariño G, BenYounes A, et al. Neuroendocrine regulation of autophagy by leptin. Cell Cycle. 2011;10(17):2917-2923.

148. Ravikumar B, Sarkar S, Davies JE, et al. Regulation of mammalian autophagy in physiology and pathophysiology. Physiol Rev. 2010;90(4):1383-1435. doi:10.1152/physrev.00030.2009

149. Gogiraju R, Hubert A, Fahrer J, et al. Endothelial leptin receptor deletion promotes cardiac autophagy and angiogenesis following pressure overload by suppressing akt/mtor signaling. Circ Heart Fail. 2019;12(1):e005622.

150. Machender RK, Nathan D. Autophagy inhibition rescues against leptin-induced cardiac contractile dysfunction. Curr Pharm Des. 2014;20(4):675-683. doi:10.2174/13816128113199990019

151. Nepal S, Kim MJ, Hong JT, et al. Autophagy induction by leptin contributes to suppression of apoptosis in cancer cells and xenograft model: involvement of p53/FoxO3A axis. Oncotarget. 2015;6(9):7166-7181. doi:10.18632/oncotarget.3347

152. Essick EE, Wilson RM, Pimentel DR, et al. Adiponectin modulates oxidative stress-induced autophagy in cardiomyocytes. PLoS One. 2013;8(7):e68697. doi:10.1371/journal.pone.0068697

153. Guo R, Zhang Y, Turdi S, Ren J. Adiponectin knockout accentuates high fat diet-induced obesity and cardiac dysfunction: role of autophagy. Biochim Biophys Acta. 2013;1832(8):1136-1148. doi:10.1016/j.bbadis.2013.03.013

154. Qi G-M, Jia L-X, Li Y-L, Li -H-H, Du J. Adiponectin suppresses angiotensin II-induced inflammation and cardiac fibrosis through activation of macrophage autophagy. Endocrinology. 2014;155 (6):2254-2265. doi:10.1210/en.2013-2011

155. Jahng JW, Turdi S, Kovacevic V, Dadson K, Li RK, Sweeney G. Pressure overload-induced cardiac dysfunction in aged male adiponectin knockout mice is associated with autophagy deficiency. Endocrinology. 2015;156(7):2667-2677. doi:10.1210/en.2015-1162 


\section{Publish your work in this journal}

The Journal of Inflammation Research is an international, peerreviewed open-access journal that welcomes laboratory and clinical findings on the molecular basis, cell biology and pharmacology of inflammation including original research, reviews, symposium reports, hypothesis formation and commentaries on: acute/chronic inflammation; mediators of inflammation; cellular processes; molecular mechanisms; pharmacology and novel anti-inflammatory drugs; clinical conditions involving inflammation. The manuscript management system is completely online and includes a very quick and fair peerreview system. Visit http://www.dovepress.com/testimonials.php to read real quotes from published authors. 